\section{Use of e-mail for consulting with patients in general practice}

I was surprised to read in the editorial 'Use of e-mail for consulting with patients in general practice ${ }^{\prime 1}$ that the author dismissed the issue of security of clinical information, stating that other industries routinely conduct transactions of a confidential nature via email, for example banking and insurance'. This is incorrect. Institutions such as banks do not use e-mail for confidential transactions because it is not secure. Their use of e-mail is limited to defined conditions and for strictly limited purposes. Secure email is possible lfor example, using public key infrastructure [PKI] or other forms of encryption) but this has had only limited use.

Although the UK Department of Health advocates the use of electronic communication between clinician and patient, there are issues of privacy, confidentiality, security, and data storage to be resolved in addition to the need, as outlined in the editorial, for health professionals to adapt to the use of this form of clinical communication.

Frances Griffiths,

Professor of Medicine in Society, Head of Social Science and Systems in Health Research Unit, Director of Research Degrees for Warwick Medical School, Division of Health Sciences, Warwick Medical School, University of Warwick, Coventry, CV4 7AL.

E-mail: f.e.griffithslawarwick.ac.uk

\section{Jonathan Cave,}

European Network of Excellence in Internet Science and University of Warwick.

\section{REFERENCE}

1. Atherton, $\mathrm{H}$. Use of e-mail for consulting with patients in general practice. Br J Gen Pract 2013; 63(608): 118-119

\section{Author's response}

Thank you for your response concerning the crucial issue of security when using e-mail for the transfer of clinical information. Rather than dismissing the issue of security I recognise that this is something that needs to be explored. Your point raises questions about what people view as 'confidential' information and this view will differ, regardless of the view of the sender. This is especially likely to be the case in a healthcare setting.

While contact between banks and insurance companies and their customers is largely routine, there are occasions where e-mail exchanges do contain information that an individual is likely to consider personal; for instance details about insurance claims or insurance policies attached to e-mails. Therefore use of e-mail by these sectors even when restricted to defined conditions and for strictly limited purposes' does not necessarily exclude confidential information.

If we then think about the healthcare setting, an individual GP has responsibility for the information they send in an e-mail, but must also respect patient autonomy with regard to their views on what is appropriate content for an e-mail. Where e-mail consultations are initiated by the patient, the patient freely makes the decision to send clinical information via e-mail. The notion of confidentiality in this scenario becomes more complex; is it as defined by the GP, or does the patient's decision override any professional judgement?

Given that GPs are already using e-mail with their patients we should be focused on finding a solution to the issue of security and confidentiality that will work in a healthcare setting, drawing on experiences with existing methods of communication and reflecting on how other sectors have managed such contact. We need formal guidance that facilitates and protects rather than restricts GPs and patients.

Helen Atherton,

University of Oxford, Primary Care Health Sciences, Radcliffe Observatory Quarter, Woodstock Road, Oxford, OX2 6GG.
E-mail: helen.athertonaphc.ox.ac.uk

DOI: 10.3399/bjgp13X668087

\section{The challenge of communication in interpreted consultations in diabetes care}

Seale is right to observe that this is the first published empirical study of interpretermediated consultations in UK primary care; in the past 10 years, with several colleagues I was unsuccessful in getting funding for such a study. The paper is shocking to the extent that it shows in one UK setting - but there is no reason to suppose this was atypical - a flagrant disregard for well-evidenced guidelines ${ }^{2-4}$ on the need for proper interpreters in consultations between health professionals and people with limited English proficiency.

One of their most glaring findings is that in interpreted consultations professionals used mostly third-person pronouns (she, his) while in non-interpreted ones almost entirely second-person forms (you, your); in other words the health professionals were saying to the interpreters does he take sugar?' They note 'Thus a concordance analysis showed that "does he" is the most common two-word phrase associated with providers' usage of "he" in these consultations (33 times), and the most common verbs occurring before "him" in provider talk in these consultations are "see", "ask", "give", "tell", and "help".

All guidance points to the importance of addressing the patient directly, "do you take sugar?', allowing the interpreter simply to relay the same words.

The various qualitative findings point to serious shortcomings in consultations interpreted by 'informal' lusually family members) interpreters, and highlight the need for proper provision.

The implication of this study, as noted by Joe Kai in his editorial, is surely that the cost of paid interpreters (whether face-to-face or a telephone service) is likely to outweigh the loss of effectiveness in diagnosis and 
management by health professionals hindered by a 'language barrier'. 5

Peter Campion,

Emeritus Professor of Primary Care

Medicine, University of Hull.

E-mail: P.D.Campionahull.ac.uk

\section{REFERENCES}

1. Seale C, Rivas C, Kelly M. The challenge of communication in interpreted consultations in diabetes care: a mixed methods study. $\mathrm{Br} J \mathrm{Gen}$ Pract 2013; DOI: 10.3399/bjgp13X663082.

2. Burnett A. Meeting the health needs of refugee and asylum seekers in the UK an information and resource pack for health workers. London: Department of Health, 2002. http://webarchive. nationalarchives.gov.uk/+/www.dh.gov.uk/ en/Publicationsandstatistics/Publications/ PublicationsPolicyAndGuidance/DH_4010199 (accessed 29 Apr 2013).

3. Department of Health, Equality and Human Rights Group. Guidance on developing local communication support services and strategies. London: DoH, 2004. http://uww.dh.gov.uk/prod consum_dh/groups/dh_digitalassets/dadh/den/ documents/digitalasset/dh 4082350.pdf laccessed 29 Apr 2013).

4. Tribe R. Asylum 4: working with interpreters. The Psychologist 2007; 20(3): 159-161.

5. Kai J. Enhancing consultations with interpreters: learning more about how. Br J Gen Pract 2013; 63(607): 66-67.

\section{Don't shoot the messenger: the problem of whistleblowing in general practice}

We agree that there are unique problems for GPs in whistleblowing." However, over 5 years we found whistleblowing on 43 occasions $(42 \%$ of the totall to be the commonest presentation of clinical poor performance in our district. ${ }^{2}$ We attribute this to having experienced people available locally who are trusted to handle concerns seriously, confidentially, and discretely.

Although action is needed to enhance whistleblowing, this must be accompanied by annual reporting of numbers of whistleblowing incidents in each district so that we may know whether there are indeed trusted people available everywhere. The lessons of several national inquiries must not be lost during times of major NHS changes.
Steve Cox,

GP, St Helens, Merseyside, WN4 OXD.

E-mail: Steve.coxasthelensccg.nhs.uk

John Holden,

GP, St Helens, Merseyside, WN4 OXD.

\section{REFERENCES}

1. Mathers N, Sillitoe L. Don't shoot the messenger: the problem of whistleblowing in general practice. Br J Gen Pract 2013; DOI: 10.3399/bjgp13X665459.

2. Cox SJ, Holden JD. Presentation and outcome of clinical poor performance in one health district over a five-year period: 2002-2007. Br J Gen Pract 2009. 59(562): $344-348$.

DOI: 10.3399/bjgp13X668050

\section{Sharing control of appointment length with patients in general practice}

We read with great interest the excellent recent paper by Sampson et al ${ }^{1}$ and note their finding that doctors and patients still shared concern about the accuracy with which patients can judge their own consultation length. 2,3,4

We recently examined patients' ability to choose between 10- and 20-minute appointment lengths. For 1 week patients were routinely asked whether they would like an appointment of 10 or 20 minutes, 10 minutes being the standard length. Appointment times were measured from the time the doctor went to fetch the patient until the patient left the consulting room.

A total of 101 consultations were studied, and of these, 91 patients requested a 10-minute consultation and 10 (10\%) requested 20 minutes. Of patients choosing a consultation length of 10 minutes, consultations lasted a mean of 11.24 minutes (median 11.1, minutes, range 2-33 minutes). Of patients choosing 20 minutes, consultations lasted a mean of 18.14 minutes (median 18, range 6.47-24 minutes). Our study was carried out in a single practice and conducted by researchers who were the GPs of the participating patients, and there was no attempt at blinding, so that doctor knowledge of the consultation rate could have altered the length of consultations. Nevertheless, our findings add to the evidence base that patients are capable of choosing a consultation length of either 10 or 20 minutes with a reasonable degree of accuracy.

We would also like to emphasise the difference between consultation length (that is, time between patient being called/ entering and leaving the consultation room) and consultation frequency (time between one patient entering and the next patient entering, or number of patients booked per hour). Reading records before a patient enters and writing up the previous patient's records takes at least 2 minutes. In our practice patients are booked at a rate of five per hour, which we feel equates to a consultation length of 10 minutes. Our findings support previous suggestions that patients are able predict their consultation length, and suggest that only $10 \%$ of patients request a longer consultation, and also the recent BJGP editorial questioning the appropriateness of the 10-minute consultation. ${ }^{5}$ We also call for some consistency of definition of appointment length, as opposed to consultation frequency.

Robert Lambourn,

GP, Wooler, Northumberland.

E-mail: robert.lambournagmail.com

Joanne Richardson,

ST3 GPStR, Wooler, Northumberland.

Elizabeth Batley,

GP, Wooler, Northumberland.

Caroline Douglas,

Practice Manager, Wooler,

Northumberland.

\section{REFERENCES}

1. Sampson R, O'Rourke J, Hendry R, et al. Sharing control of appointment length with patients in general practice: a qualitative study. $\mathrm{Br} J \mathrm{Gen}$ Pract 2013; DOI: 10.3399/bjgp 13X664234.

2. Harrison AT. Appointment systems: feasibility of a new approach. Br Med J (Clin Res Ed) 1988; 294(6585): 1465-1466.

3. Lowenthal $L$, Bingham E. Length of consultation: how well do patients choose? J R Coll Gen Pract 1987; 37(304): 498-499.

4 Lambourn R. Can patients choose appointment length? Br J Gen Pract 2003; 53(497): 969-970.

5. Silverman J, Kinnersley P. Calling time on the 10-minute consultation. Br J Gen Pract 2012; 62(596): 118-119.

DOI: 10.3399/bjgp13X668096 